\title{
The Effects of Paper and Palm Kernel Shell on Mechanical Properties of Sawdust Briquettes
}

\author{
M. A. Akintunde \\ Department of Mechanical Engineering The Federal University of Technology, PMB 704, Akure, Nigeria
}

\begin{abstract}
Handling and preservation of composite briquettes, most especially during transportation, required adequate knowledge of its mechanical properties, such as density, stress, strain, young modulus and breaking strength. In this work some mechanical properties of composite briquettes, made out of sawdust, palm kernel shell and paper paste, were examined. The composite briquettes were prepared in such as way that the densities within the samples range between $1.0 \mathrm{~g} / \mathrm{cm}^{3}$ and $1.1 \mathrm{~g} / \mathrm{cm}^{3}$. This is to minimize the effect of density variation. Also the preparations were done under the same temperature, so that the effect of temperature on the mechanical properties can be removed at the unset of the experimentation. Experimental results show that, the young modulus of the composite briquettes increases with increase in the value of palm kernel shell and decreases with increase quantity of paper paste when the samples were loaded in compression. A difficult situation was met when the samples were loaded in tension because of the brittleness of the samples. However this shows that the addition of palm kernel shell increases hardness of the composite briquettes, while the addition of paper paste improves handling effect. On the other hand, as the quantity of paper increases more energy is required to form the briquettes.
\end{abstract}

Key words: composite, briquettes, mechanical properties, stress, strain, deflection, handling, transportation.

\section{Introduction}

In the past decades, researchers have been focusing on alternative fuel resources to meet the everincreasing energy demand and to avoid dependence on fossil fuel. One of the promising alternatives is the biomass because of its renewability, abundance and positive environmental impacts resulting in no net release of carbon dioxide and very low sulfur content, (Karunanity et al., 2012). Biomass on the other hand is very difficult to handle, transport, store, and utilize in its original form, this is due to factors which can include: high moisture content; irregular shape and size; and low bulk density. To guarantee the quality of biomass briquettes in the handling and usage processes, sufficient durability of briquettes have to be provided. According to Menind et al., (2012) briquettes must be consistent or otherwise cracks, scratches would appear and fine elements would separate and that is/would be not acceptable. Briquettes with higher density have longer burning time.

Durability of solid biomass briquettes is regulated by standard: such as: solid-bio-fuels- methods for the determination of mechanical durability of pellets and briquettes - parts: briquettes LVS EN 15210-2: 2010. Here the durability is the measure of the resistance of densified fuels towards shocks and/or abrasion as consequences of handling and transportation processes. The test sample is subjected to controlled shock by collision of briquettes against each other and against the walls of a defined rotating test chamber. The durability is calculated from the mass of sample remaining after separation of abraded and fine broken particles. The size of the sample shall conform to the requirements of corresponding technical specifications and shall be at least 15 $\mathrm{kg}$, (Kakitics, et al; 2011).

Standard O-Norm M7135 defines briquettes density value for group Hp (wood briquettes) and for group Rp (crust briquettes) more than $1.12 \mathrm{~kg} / \mathrm{dm}^{3}\left(\mathrm{~g} / \mathrm{cm}^{3}\right)$, and for other briquettes this value must be more that $1 \mathrm{~kg} / \mathrm{dm}^{3}\left(\mathrm{~g} / \mathrm{cm}^{3}\right)$. Standard DIN 51731 defines interval of briquettes density values from 1 to $1.4 \mathrm{~g} / \mathrm{cm}^{3}$. As reported by Plistil et al., (2005), the basic standards for the solid biofuels developed Technical CommitteeCEN/TC 335 Solid Biofuels. Standard EN 149561: Solid Biofuels- fuel specification and classes determine the briquettes density $\rho=0.8-1.2 \mathrm{~g} / \mathrm{cm}^{3}$. The density of $\rho>1.0 \mathrm{~g} / \mathrm{cm}^{3}$ is recommendable for high quality wood briquettes. This value had been used for evaluation of herbaceous materials densification results.

Apart from density and consistency, another factor that must be considered is the issue of grain sizes. Researchers have worked on different grain sizes of sawdust in the recent past. Sosu et al., (2011) worked on particles sizes (d) ranges between $0.8 \mathrm{~mm}$ and $4.8 \mathrm{~mm}$. These sizes were grouped into three groups $\mathrm{A}(\mathrm{d} \leq 0.8$ $\mathrm{mm})$ call fine particles; $B(0.8 \mathrm{~mm} \leq \mathrm{d} \leq 1.1 \mathrm{~mm})$ tagged medium size and $\mathrm{C}(1.1 \mathrm{~mm} \leq \mathrm{d} \leq 4.8 \mathrm{~mm})$ called coarse size. The effects of these grain sizes were evaluated on mechanical properties of composite sawdust briquettes. Their results show that the size of grain has no significant effect on the mechanical properties examined. 
Akintunde and Seriki (2012) worked on particle size ranges between $0.75 \mathrm{~mm}$ and $1.70 \mathrm{~mm}$. Their results indicated an increase in calorific values as the particle sizes decreases. This is actually due to the increase in the total surface area of the particle. There was no report on the effects of particle sizes on the mechanical properties.

Researchers have worked on many composite briquettes: Sosu et al., (2011) worked on palm fruit fibre/sawdust composite briquettes; Adegoke and Mohammed (1999) worked on palm kernel shell/sawdust composite briquettes; Maki et al., (2012) worked on maize stock/sawdust composite briquettes; Ajuitse (2011) reported on coconut husk/sawdust briquettes; Kakitis et al., (2011) reported on wheat straw, hemp stalks, reed and reed composition with peat biomass densification, so also many other researchers; such as: Kaliyan et al, (2009) and others. There is no available report on paper as composite material available except that of Akintunde and Seriki (2012), which is mainly on calorific value and not on mechanical properties.

This work therefore is aimed at evaluating the effects of paper paste and palm kernel shell on the mechanical properties of composite briquettes. Composite materials can be either natural or artificial. It is a substance that is made of a combination of two or more different materials. For instance, the briquettes used in this work consist of sawdust, palm kernel shell and paper. A composite material can provide superior and unique mechanical and physical properties because it combines the most desirable properties of its constitutions while suppressing their least desirable, (Sosu et al., 2011). The constituents retain their identities in the composite; that is, they don't dissolve or otherwise merge completely into each other although they act in concert, (DoD, 2002).

\section{Materials And Method}

Menind et al., (2012) reported that briquettes quality can be influenced by many parameters. Five of them are having most significant effect to briquettes properties. These parameters are material type, pressing temperature, compacting pressure, fraction largeness and material moisture contact. In order to take these parameters into consideration, the sawdust used was taken from the same wood teak; (Akintunde and Seriki, 2012); $115^{\circ} \mathrm{C}$ pressing temperature was used, as suggested by Menind et al., (2012), compacting pressure of 212 $\mathrm{MPa}$, suggested by Kakitis et al., (2011) was use, the moisture content was kept between $8 \%$ and $10 \%$ as suggested by many researchers for quality briquettes. However, the fractional largeness of the composite (viz, sawdust paper and palm kernel shell) was varied in order to study their effects on the mechanical properties. Sawdust from teak log was collected from a sawmill in Akure and dried for three weeks when a constant weight was recorded. This was sieved to obtain a grain size ranges between $0.75 \leq \mathrm{d} \leq 1.0 \mathrm{~mm}$. Equal gain sizes were obtained in the case of palm kernel shell also. The shell was treated with hot water to remove residual oil for it.

Since sawdust was used as the basic material, each composite sample, except the control which is $100 \%$ sawdust, consists of, at least, $66.67 \%$ of sawdust. Eight different samples were prepared. The first sample denoted as A, was made of $100 \%$ of sawdust this act as the control. The other seven samples were made of ratios (by mass) of components of sawdust, palm kernel shell and paper as shown in Table 1.

Table 1 composition of briquettes samples by mass

\begin{tabular}{|c|c|c|c|c|}
\hline S/N & Code & Sawdust & Paper & Palm Kernel \\
\hline 1. & B & 100 & 50 & 0 \\
\hline 2. & C & 100 & 45 & 5 \\
\hline 3. & D & 100 & 35 & 15 \\
\hline 4. & E & 100 & 25 & 25 \\
\hline 5. & F & 100 & 15 & 35 \\
\hline 6. & G & 100 & 5 & 45 \\
\hline 7. & I & 100 & 0 & 50 \\
\hline
\end{tabular}

Equal amounts of starch was added to each sample in a mixer and mixed thoroughly, the briquettes were formed by transferring the mixture to a cylindrical mould in a briquetting making machine developed by Adegoke et al., (2006). The briquettes samples were made under controlled temperature, the density within the samples varies between $1.0 \mathrm{~g} / \mathrm{cm}^{3}$ and $1.1 \mathrm{~g} / \mathrm{cm}^{3}$. This falls within the suggested range in the literature. Test were carried out to evaluate young`s modulus of elasticity, fracture load, maximum deflection and compressed strength. The entire samples were cylindrical shaped of equal dimensions, $60 \mathrm{~mm}$ high and $30 \mathrm{~mm}$ diameter. The methods used in carrying out the tests, follows those suggested by Kakitis et al., (2011) and Sosu et al., (2011). However more explanation can be obtained from the works of Ajuitse (2012) and Seriki (2012).

After the measurements, young's modules, (E) was calculated by dividing the tensile stress $(\sigma)$ by tensile strain $(\varepsilon)$ in the elastic region of the stress- strain curve:

$$
\sigma=\frac{\text { load applied }(F)}{\text { original cross-sectional area }(A o)}=\frac{F}{A o}
$$




$$
\begin{aligned}
& \varepsilon=\frac{\text { change in length } \Delta t=L O-L}{\text { original lengtn }(L O)} \\
& E=\frac{\text { tensite stress }}{\text { tensite strain }}=\frac{\sigma}{\sigma}=\frac{F / A O}{A O / \Delta}=\frac{f L O}{A O \Delta L}
\end{aligned}
$$

where: $F$ is the applied force; $A_{o}$ is the original cross- sectional area; $\Delta L$ is the amount by which the length charge; and $L_{o}$ is the original length.

During the experimental studies, samples were erected in between two flat plates and applied force was measured together with the compression pressure. The same method was repeated under the tensile conditions. Sample also was hanged like count lever to measure deflection.

Deflection under various loads were measured, the measured deflections were used to estimate, modulus, fraction load and compressive strength.

\section{Results And Discussion}

During sample preparation, it was noticed that the force required to form sample (B) is almost double that of A. This may be attributed to the fact that paper has low density as compare to the type of wood used. This shows that more energy is required in forming B which is made up of 2:1 ratio of sawdust to paper. As the quality of paper reduces less energy is required to achieve required density.

As showing Fig. 1, the fractional force required for sample B is almost twice that of A. So also, as the quantity of paper reduces the required fractional load decreases. In the same figure, the energy required to break samples G, H and I are almost the same as that of A. Less energy is required to form the briquettes when the mixture of 2:1 ratio of sawdust to palm kernel shell is used.

As shown in Fig 2, the same trend as that of Fig. 1, was obtained. The figure shows that sample B's deflection before fracture is almost twice as that of A. This shows that malleability increases with the amount of paper. While, on the other hand, the more the quantity of palm kernel shell the more brittle the samples becomes. Also, it can be observed that the relative deflections for samples G and I are almost the same as that of the control (sample A). From the previous studies, composite briquette with palm kernel shell as additive give more calorific values more than that of pure sawdust briquettes, Akintunde and Seriki (2012); Adegoke and Mohammed (1999). Hence samples $\mathrm{G}$ and $\mathrm{H}$ will be more economical if brittleness is overlooked. On the other hands for durability, handling and transportation, briquettes $\mathrm{E}$ and $\mathrm{F}$ will be more economical.
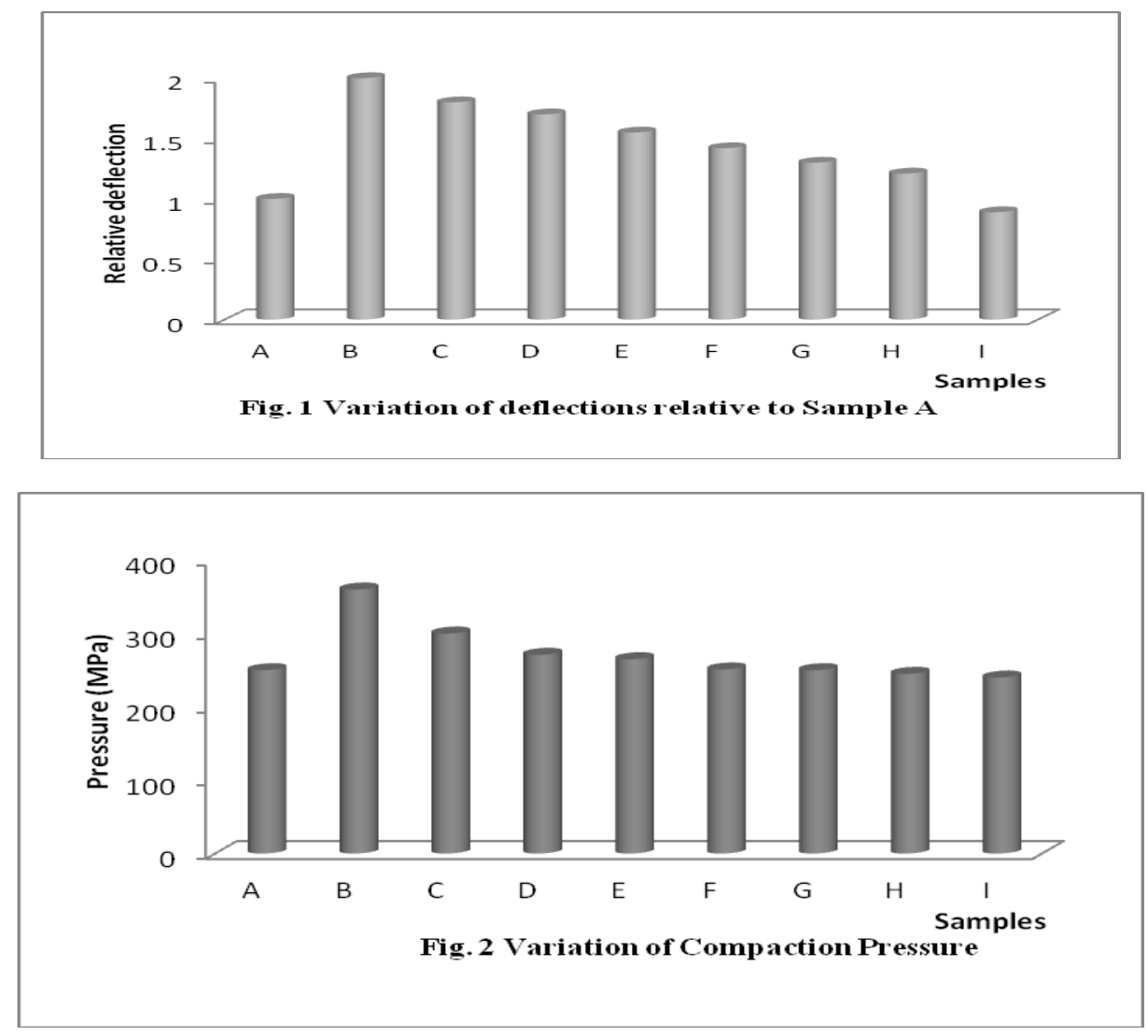
As shown is Fig 3, the required splitting force decreases with increasing quantity of palm kernel shell and decreasing paper paste. This shows that the splitting force is inversely proportional to quantity of palm kernel shell and directly proportional to the quantity of paper. This shows that additional of paper gives rise to durability as well as malleability. Hence, addition of paper improved durability of the briquettes and it can easily be handled.

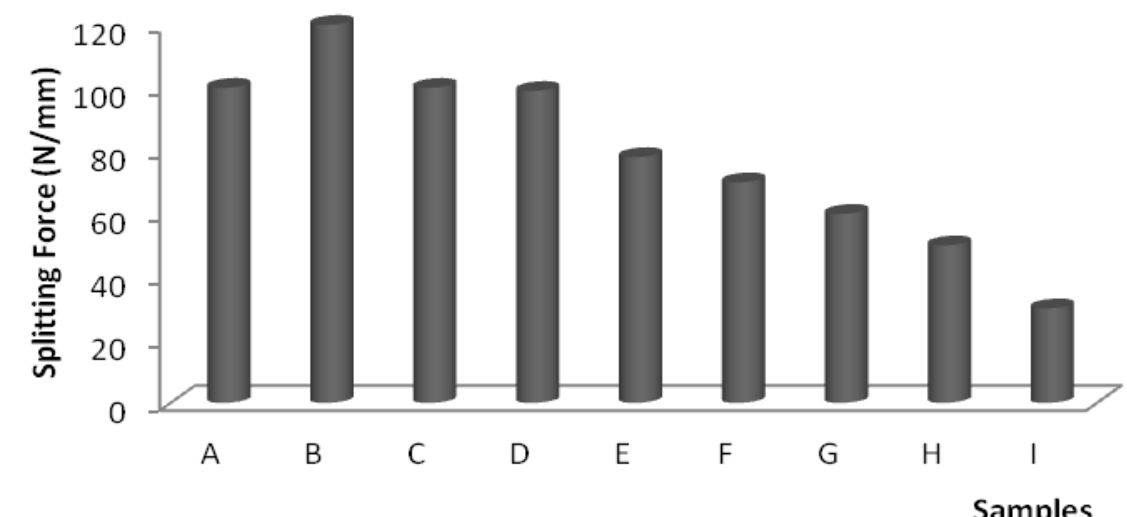

Fig. 3 Variation of Splitting Force with Samples

Fig 4, shows the variation of both stress and strain when the samples were tested under tensile forces. As can be seen in the figure, stress is directly proportional to strain within the elastic limit of the samples. The ratios stress: strain for sample A and B are almost equal. The result for sample I indicated that sample I is more brittle as compared to other samples. Also, the result shows that sample I cannot sustain more load in tension as compared with A and B. In Fig. 5 the results show that sample I can sustain more load in compression than samples A, B and other samples.

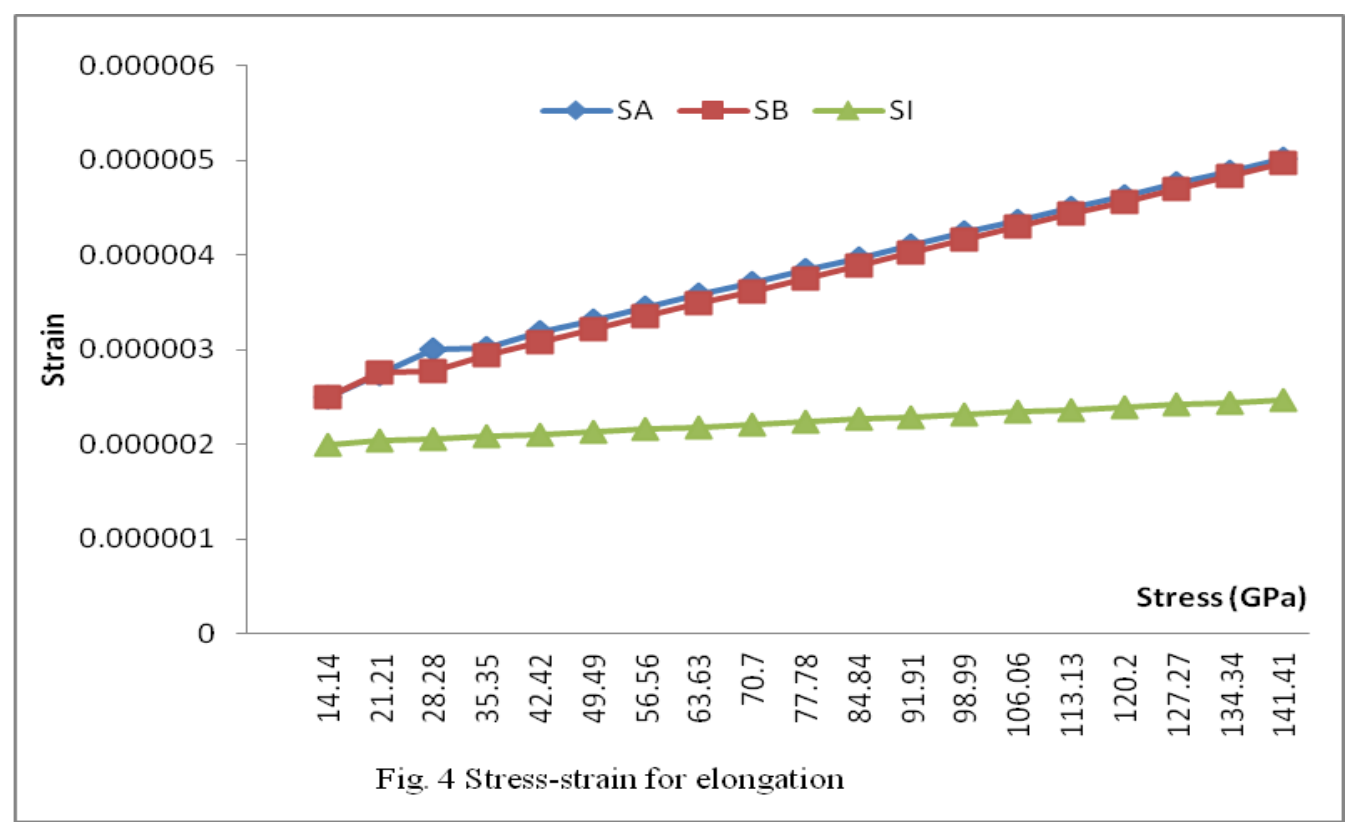

When the samples are under tensile load, it was very difficult to estimate the young modulus. This is due to the brittleness of the samples. Fig 6 shows the estimated young moduli of the samples loaded in compression. As shown in the figure, samples A, B and C showed almost the same value. These three samples consist of less palm kernel shell. As the quantity of palm kernel shell increases, the value of young modulus increases with the percentage of palm kernel shell. 

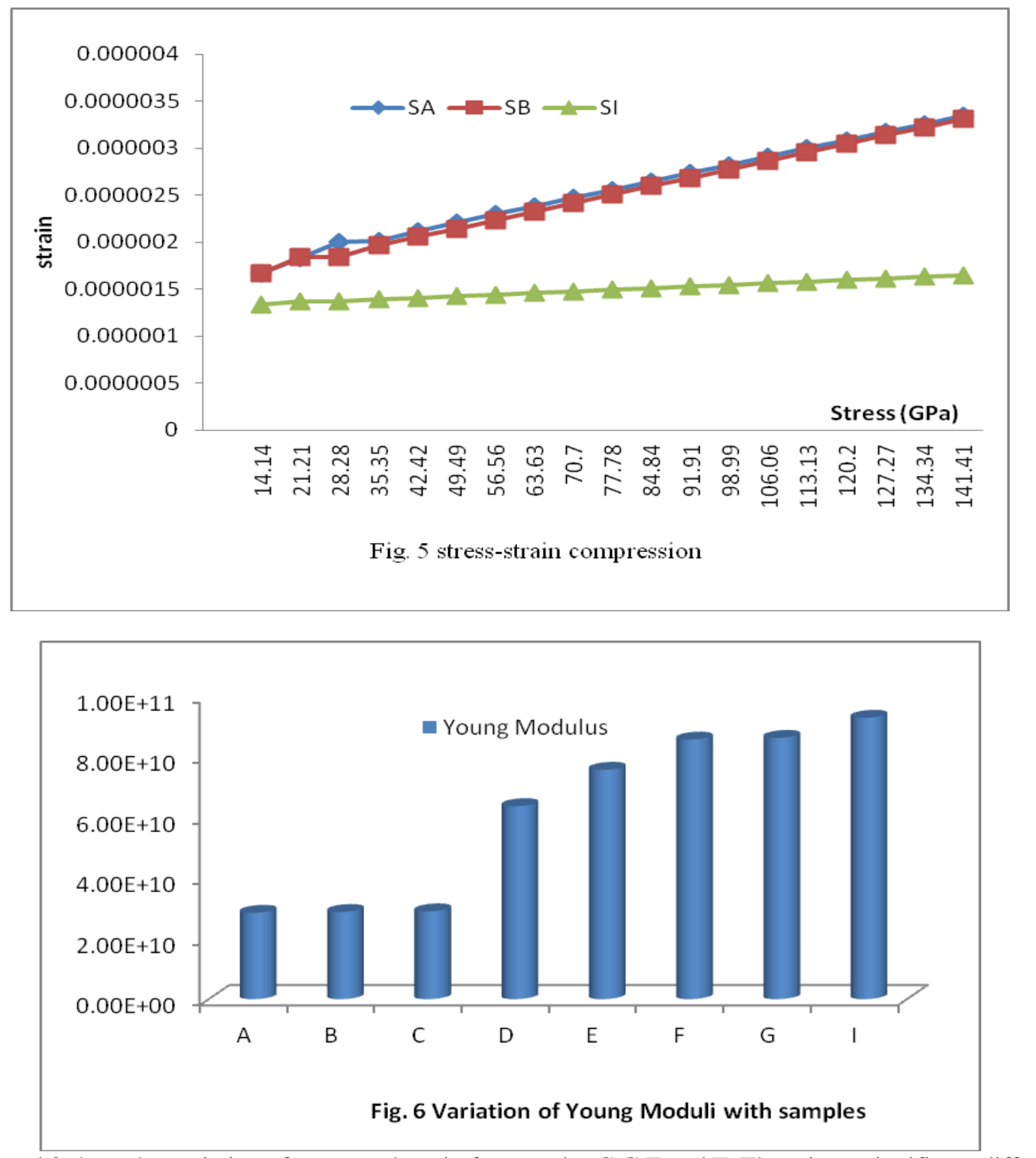

Figs 7 and 8 show the variation of stress and strain for samples C,G,E and F. There is no significant difference between the treads in Figs 7 and 8 and those of Figs 4 and 5.

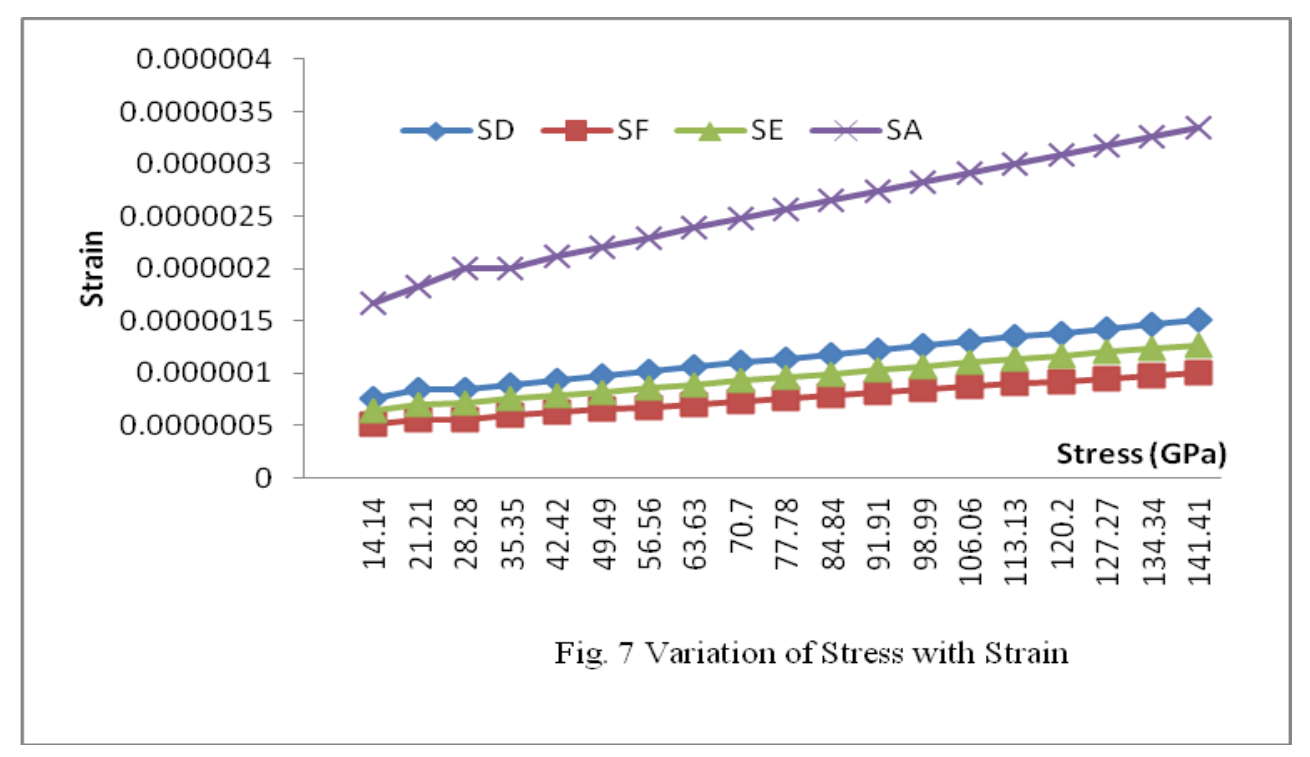




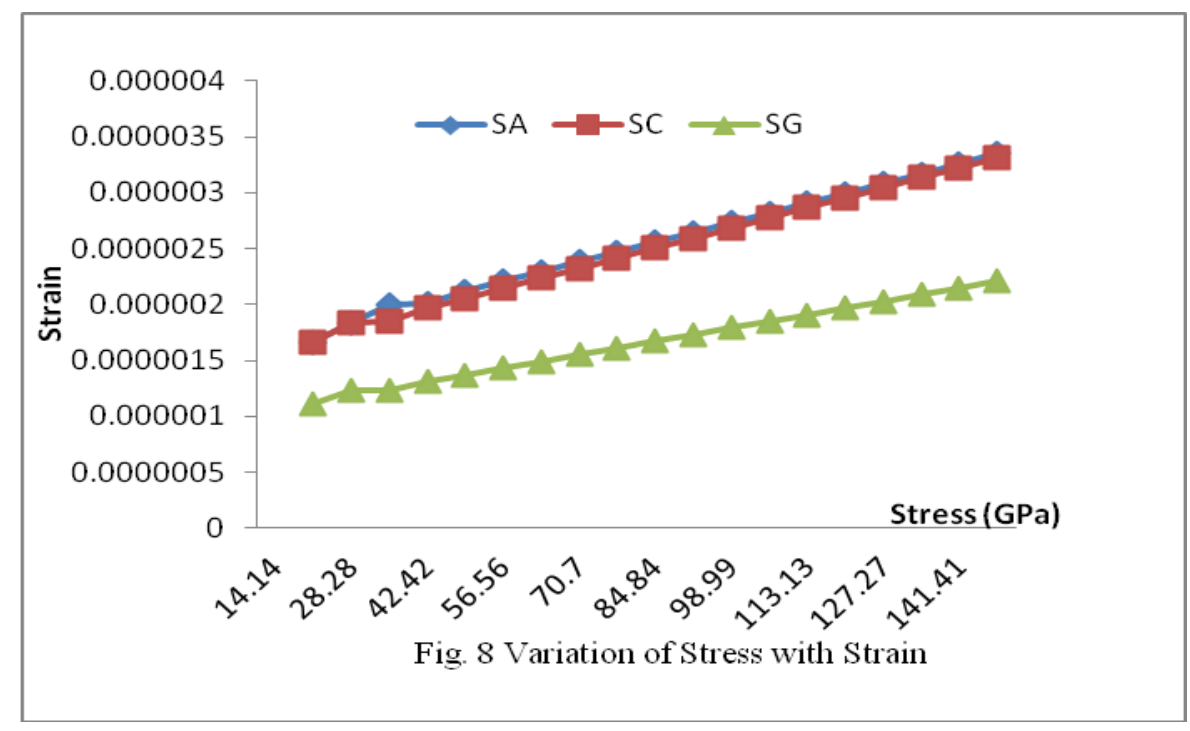

\section{Conclusion}

The aim of this work is to examine the effects of paper and palm kernel shell on some of the mechanical properties of composite sawdust briquettes. Sawdust briquettes were prepared with various additions of both palm kernel shell and paper paste. A pure sawdust briquette was used as control for the experimentation. The preparation of the samples were done in a way to eliminate the effects of temperature, moisture content, grain sizes and density. The densities of all the samples were almost equal, and they are within the acceptable values as noticed in available literature. To achieve this, the compaction force (or pressure) require to prepare different samples varies.

Experimental results show that, the young modulus of the composite briquettes increases with increase in the value of palm kernel shell and decreases with increase quantity of paper paste when the samples are loaded in compression. A difficult situation was met when the samples were loaded in tension because of the brittleness of the samples. Hence, addition of palm kernel shell increases hardness of the composite briquettes, while the addition of paper paste improves handling effect. However as the quantity of paper increases more energy is required to form the briquettes. For handling and transportation, addition of paper up to $23 \%$ indicated a significant durability.

\section{Reference}

[1] Adegoke, CO and Mohammed, TI (1999)", The effects of palm kernel shell on calorific value of sawdust briquettes". Journal of Applies Science. Vol 10, No 2 pp 25-37

[2] Adegoke, CO, Mohammed, TI and Alatise, MO (2006), "Development of a briquettes making machine". Global Journal of Engineering and Technology. Vol 3, No 2, pp 231-240.

[3] Ajuitse, ON (2012), "Investigation of sawdust briquette as high grade fuel Ph.D Thesis, Department of Mechanical Engineering, the Federal University of Technology, Akure. (Unpublished).

[4] Akintunde, MA and Seriki, ME (2012), "Effect of paper paste on the calorific value of sawdust briquette". International Journal of Modern Engineering Research (IJMER), Inpress.

[5] DoD (2002), Department of Defence. "Composite materials handbook". 3: 35. (MIL-HDBK - 17 - 3F). www.lib.ucdavis.edu/dept/pse/resources/fulltext/HDBK17-3F.pdf. (as at November 6, 2012).

[6] Kakits, A; Nulle; I; and Ancans, D (2011), "Mechanical properties of composity biomass briquettes". Proceedings of the $8^{\text {th }}$ International Scientific and Practical conference, pp $175-183$.

[7] Kaliyan, N; Morey, RV; White, MD and Doering, A (2009), "Roll press briquettes and pelleting of corn stover and switchgrass". Transaction of the ASABE. Vol. 52 No 2, pp $543-555$.

[8] Karunanithy, C; Wang, Y; Muthukumarappan, K and Pugalenghi, S. (2011), "physiochemical characterization of briquettes made from different feedstock". Biotechnology Research International. Article ID 165202, pp 1 -9.

[9] Kuti, OA (2003), "Evaluation of composite sawdust briquettes as a high grade fuel for Domestic Cooking". Journal of Engineering and Engineering Technology, FUTA. Vol 2, No 2, pp 109-115.

[10] Krizan, P; Matus, M; Soos, L; Kers, J; Peetsalu, P; Kask, U; and Menind, A (2011), "Briquetting of municipal wastes by different Technologies for quality and properties evaluation”. Agronomy Research, Vol. 19, pp $115-123$.

[11] Maki, KC; Pelkman, CL; Finocchiaro, EI; Kelley, KM; Lawless, AL; Schid, AB and Rains, TM (2012), "Resistant Starch from High-Amylose Maize Increases Insulin Sensitivity in Over-weight and Obese Man”. Journal of Nutrition, Vol. 142, No. 4, pp 717 723.

[12] Menind, A; Krizan, P; Soos, 1; Matus, M and Kers, J (2012), "Optimal conditions for valuation of wood waste by briquetting". $8^{\text {th }}$ International DAAAM Balitic conference, 19 - 21 April, 2012. Tallinn, Estonia.

[13] Seriki, ME (2012), "Effects of paper paste on the calorific value of sawdust briqueltes". M. Eng Thesis, Department of Mechanical Engineering, the Federal University of Technology, Akure. (Unpublished).

[14] Sosu, EK; Hasford, F and Dadson, ABC (2011), "Study of mechanical properties of composite materials made from palm fruit fibre and sawdust". Research Journal of Applied Science, Engineering and Technology. Vol 3, No 12 pp 1441-1444. 